\title{
Immunohistochemical Study of Endothelial Nitric Oxide Synthase in the Trigeminal Ganglia of a Crotaline Snake Trimeresurus flavoviridis
}

\author{
Changjong MOON ${ }^{1,2)}$, Shin-ichi TERASHIMA ${ }^{1)}$ and Taekyun SHIN ${ }^{2) *}$ \\ ${ }^{1)}$ Department of Physiology, University of the Ryukyus School of Medicine, Nishihara-cho, Okinawa 903-0215, Japan and ${ }^{2)}$ Department \\ of Veterinary Medicine, Cheju National University, Jeju 690-756, Republic of Korea
}

(Received 10 December 2003/Accepted 30 March 2004)

ABSTRACT. The immunoreactivity of constitutive endothelial nitric oxide synthase (eNOS) was studied in the trigeminal ganglia (TG) of a crotaline snake, Trimeresurus flavoviridis. eNOS immunoreactivity was found in TG neurons of different sizes. The percentage of eNOS-positive TG neurons was significantly higher in the mandibular division than in the infrared-related divisions, the maxillary division and ophthalmic ganglion $(p<0.001)$. These findings suggest that eNOS in the TG of crotaline snakes is involved in constitutive neurotransmission in the TG, and is minimally involved in processing in the infrared-sensory system. KEY WORDS: crotaline snake, endothelial nitric oxide synthase, trigeminal ganglion neuron.

J. Vet. Med. Sci. 66(8): 1007-1009, 2004

Crotaline snakes possess a pair of pit organs that are infrared receptors. One pit organ is located on each side of the face, roughly midway between the nostril and the eye. Neurons in the trigeminal ganglia (TG) of these snakes transmit infrared sensory information from the pit organs to the central nervous system [8].

Nitric oxide (NO) is believed to serve as a neurotransmitter or modulator in a number of different processes, it is synthesized from L-arginine via nitric oxide synthase (NOS) $[1,3,11]$. NOS and reduced nicotinamide adenine dinucleotide phosphate diaphorase (NADPH-d) histochemistry have provided powerful evidence that NO is synthesized in a number of specific groups of neurons and glial cells $[4,6]$. In the Reptilia, NOS isoforms identified in the turtle brain have conserved consensus sequences for NADPH binding sites [2]. However, NADPH-d activity does not colocalize with NOS immunoreactivity in some regions $[7,10,12]$. Previously, constitutive neuronal NOS (nNOS) and NADPH-d reactivity were found in the TG of infrared-sensitive snakes, suggesting that they are involved in neurotransmission in the TG [7,10]. The endothelial isoform of nitric oxide synthase (eNOS), a constitutive NOS, ensures enzymatic production of nitric oxide (NO) in endothelial and other cell types, such as retinal ganglion cells, vestibular hair cells, and astrocytes $[4,5,13]$. However, little is known of the involvement of constitutive eNOS in the snake TG.

This study examined the expression of eNOS in the maxillary, mandibular, and ophthalmic divisions of trigeminal ganglion neurons of an infrared-sensitive snake, Trimeresurus flavoviridis.

Six crotaline snakes of both sexes weighing 400-700 g were used. The animals were anesthetized with isoflurane before being perfused through both carotid arteries with cold $\left(4^{\circ} \mathrm{C}\right)$ snake Ringer's solution $(0.81 \% \mathrm{NaCl}, 0.022 \%$

\footnotetext{
* Correspondence to: Shin, T., Department of Veterinary Medicine, Cheju National University, 1 Ara-1-dong, Jeju 690-756, Republic of Korea.
}

$\mathrm{KCl}, 0.026 \% \mathrm{CaCl}_{2}$ ) and fixative containing $4 \%$ paraformaldehyde (PFA) in $0.1 \mathrm{M}$ phosphate-buffered saline (PBS, pH 7.4). The TG and brain were removed and processed for paraffin embedding. The pit membranes were also removed and stored in fixative at $4^{\circ} \mathrm{C}$ until immunohistochemical processing.

Immunostaining of eNOS was performed as in a previous study [10]. For cell size and modality analyses, we used an immunofluorescence method and confocal microscopy (OLYMPUS FLUOVIEW ${ }^{\circledR}$, Olympus, Tokyo, Japan). Briefly, sections were incubated with blocking serum and primary mouse anti-eNOS antibody (1:200 dilution, Transduction Laboratories, Lexington, KY). The sections were exposed to fluorescein-5-isothiocyanate (FITC)-conjugated goat anti-mouse IgG (1:50 dilution; Zymed Laboratories Inc, San Francisco, CA) and examined on a confocal microscope. The cross-sectional area of FITC-labeled cell bodies that contained the nuclear profiles was measured with FLUOVIEW (version 2.0) software and recorded on glossy prints, as in our previous study [10].

We evaluated statistical significance with a one-way ANOVA using the post-hoc Student-Newman-Keuls procedure for multiple comparisons. Differences with $p<0.05$ were considered significant.

Immunoreactivity of eNOS appeared in neurons of various shapes and sizes in all three divisions (maxillary, mandibular, and ophthalmic) of the TG (Fig. 1). However, satellite cells and Schwann cells in the TG were eNOS negative.

A previous study using HRP labeling of neurons from the pit organ to the TG revealed HRP-positive infrared-sensory neurons in the ophthalmic ganglion and maxillary division of the maxillo-mandibular ganglion, but not in the mandibular division [8].

In all, 15.7\% (136/864) of TG neurons were eNOS positive. As shown in Table 1, the percentages of eNOS-positive neurons (positive neurons/total neurons $\times 100$ in each 

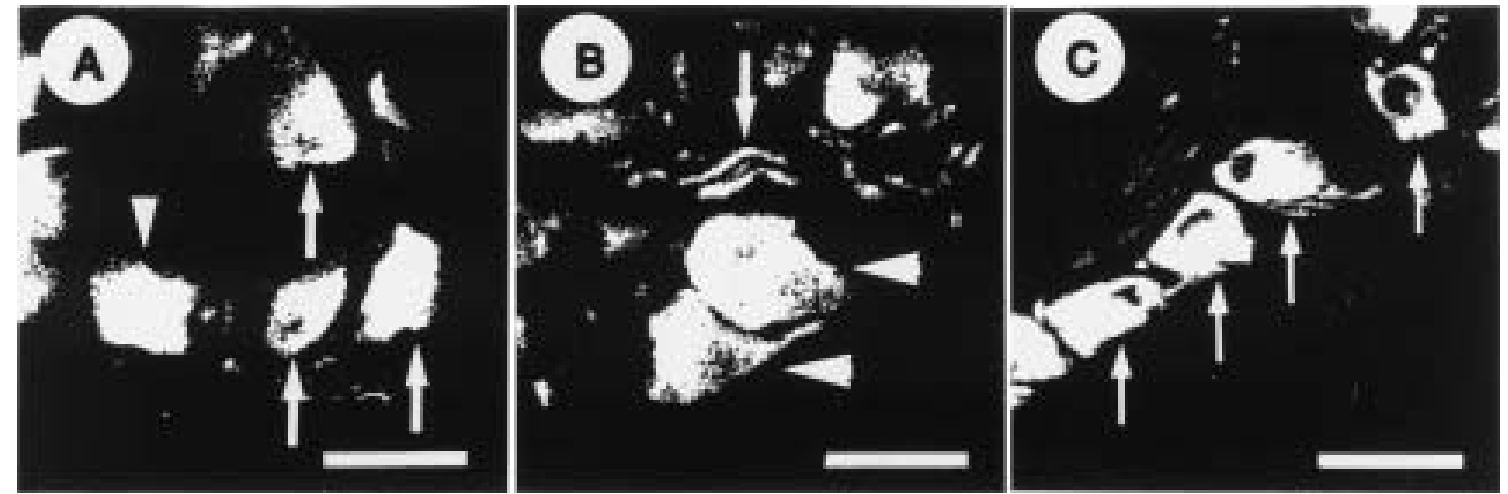

Fig. 1. Microphotographs of eNOS in the TG of infrared-sensitive snakes. A, eNOS-positive immunoreaction is seen in most small (arrows) and a few medium-sized (arrowhead) neurons in the maxillary division of the TG. B, eNOS-positive immunoreaction in a capillary (arrow), and large and medium-sized neurons (arrowheads) in the mandibular division. C, eNOS expressed in small neurons in ophthalmic ganglion (arrows). Digital confocal images of eNOS-positive neurons were obtained from a single optical section. Scale bars $=50 \mu \mathrm{m}$.

Table 1. Percentage of eNOS-positive neurons relative to all TG neurons of infraredsensing crotaline snakes

\begin{tabular}{lccc}
\hline & Maxillary division & Mandibular division & $\begin{array}{c}\text { Ophthalmic } \\
\text { ganglion }\end{array}$ \\
\cline { 2 - 4 } Positive neurons $(\%)^{\mathrm{a})}$ & $3.73 \pm 1.21$ & $23.40 \pm 2.29 *$ & $6.28 \pm 0.24$ \\
\hline
\end{tabular}

a) Data are expressed as the mean \pm S.E.M. The data were obtained from 315,297 , and 252 neurons from three snakes. ${ }^{*}, p<0.001$.

division, $\mathrm{n}=3$ ) in the maxillary division (about 3.5-fold lower) and ophthalmic ganglion (about 6-fold lower) differed significantly from that in the mandibular division of the TG $(p<0.001)$. This difference in the distribution of eNOS expression among the divisions suggests that eNOS is not associated with infrared sensory processing in infraredsensitive snakes directly. This postulate is further supported by the fact that eNOS was not detected in the infraredrelated areas of the pit membrane (terminal nerve masses and infrared nerve fibers) or central nervous system (lateral descending nucleus and nucleus reticularis caloris) (data not shown); moreover, NADPH-d was not present in these areas [7].

TG neurons of all sizes contained eNOS. We defined three arbitrary classes of eNOS-positive neurons by size, as in our previous study [10]: small neurons were $0-599 \mu \mathrm{m}^{2}$ (major diameter: $33.75 \pm 2.60 \mu \mathrm{m}$, minor diameter: $21.13 \pm$ $1.42 \mu \mathrm{m})$; medium-sized neurons were $600-1199 \mu \mathrm{m}^{2}$ (major diameter: $43.80 \pm 1.77 \mu \mathrm{m}$, minor diameter: $30.95 \pm$ $1.35 \mu \mathrm{m}$ ), and large neurons were $1200-2199 \mu \mathrm{m}^{2}$ (major diameter: $55.33 \pm 2.57 \mu \mathrm{m}$, minor diameter: $42.42 \pm 2.37$ $\mu \mathrm{m})$.

Within the individual populations in the TG, eNOS-positive neurons were more abundant among the large $(20.3 \%$, $12 / 59)$ and small neurons $(34.8 \%, 8 / 23)$ than among medium-sized neurons $(12.8 \%, 20 / 156)$. There is general agreement that neurons of different sizes play different roles in the nervous system. In the TG of infrared-sensitive snakes, the infrared-sensory neurons (temperature neurons)

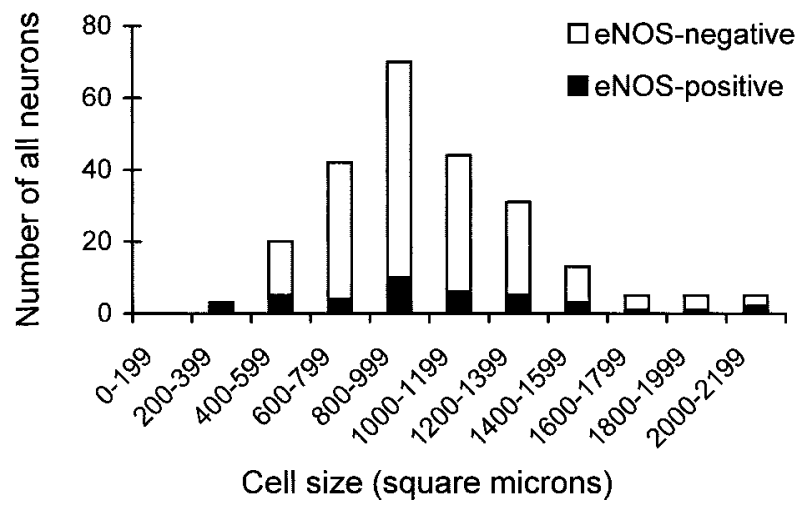

Fig. 2. Histograms showing the cell-size spectrum of eNOS-positive and eNOS-negative neurons in the TG. These data were obtained from 238 TG neurons.

are mostly medium-sized (major diameter: $42.1 \pm 5.3 \mu \mathrm{m}$, minor diameter: $31.2 \pm 4.7 \mu \mathrm{m}$ ) [12]. They are similar in size to nociceptive A- $\delta$ neurons, smaller than tactile and vibrotactile neurons, and larger than the $\mathrm{C}$ nociceptive neurons of the TG [9]. Our results suggest that the majority of eNOS-positive immunoreactivity occurs in small $\mathrm{C}$ mechanical nociceptive neurons and large tactile or vibrotactile neurons. Moreover, a small percentage of mediumsized eNOS-positive neurons may be medium-sized nociceptive A- $\delta$ neurons in the TG. In addition, the observed pattern of eNOS immunoreactivity is similar to that of neuronal 
NOS reported previously [10]. A minor difference is that the percentage of eNOS expression in the maxillary division (about $3.7 \%$ of all neurons) is about 2 -fold lower than that of nNOS (about 6.9\%). Based on cell size, the eNOS-positive population differs somewhat from the population of NADPH-d-positive neurons: NADPH-d-positive neurons were identified mostly in the small TG neurons [7], whereas eNOS was expressed in both large and small neurons in the TG. This phenomenon of non-colocalization of NADPH-d and NOS was shown in a previous study [12].

This is the first study to immunolocalize eNOS in the TG neurons of infrared-sensitive snakes, and we postulate that eNOS acts as a neurotransmitter in TG neurons, possibly by generating physiological NO, while it is less involved in infrared-sensory processing.

ACKNOWLEDGMENT. This study was supported by a grant from the Korean Health 21 R \& D Project, the Ministry of Health \& Welfare, Republic of Korea (02-PJ1-PG1021305-0003).

\section{REFERENCES}

1. Bredt, D. S. and Synder, S. H. 1992. Neuron 8: 3-11.
2. Bruning, G., Wiese, S. and Mayer, B. 1994. J. Comp. Neurol. 348: 183-206.

3. Bult, H., Boeckxstaens, G. E., Pelckmans, P. A., Jordaens, F. H., Van Maercke, Y. M. and Herman, A. G. 1990. Nature (Lond.) 345: 346-347.

4. Gabbott, P. L. and Bacon, S. J. 1996. Brain Res. 714: 135-144.

5. Heinrich, U. R., Lioudyno, M., Maurer, J., Mann, W., Guth, P. S. and Forstermann, U. 2003. J. Electron Microsc. (Tokyo) 52: 197-206.

6. Hope, B. T., Michael, G. J., Knigge, K. M. and Vincent, S. R. 1991. Proc. Natl. Acad. Sci. U. S. A. 88: 2811-2814.

7. Jiang, P. J. and Terashima, S. 1996. Brain Res. 713: 168-177.

8. Kishida, R., Terashima, S., Goris, R. C. and Kusunoki, T. 1982. Brain Res. 241: 3-10.

9. Liang, Y. F., Terashima, S. and Zhu, A. Q. 1995. J. Comp. Neurol. 360: 621-633.

10. Moon, C., Terashima, S., Ahn, M., Kang, J. and Shin, T. 2002. Neurosci. Lett. 319: 21-24.

11. Nathan, C. and Xie, Q.W. 1994. Cell 78: 915-918.

12. Spessert, R., Wohlgemuth, C., Ress, S. and Layers, E. 1994. J. Histochem. Cytochem. 42: 569-577.

13. Sumamoto, Y., Yamashita, K., Takumida, M., Okada, K., Mukai, S., Shinya, M., Yamashita, H. and Mishima, H. K. 2002. Brain Res. 933: 118-129. 